\title{
Non-Invasively Detecting Blood Vessels during Laparoscopic/Robotic Procedure
}

\section{Jae Kim*}

University of Central Florida College of Medicine, Orlando, United States

\begin{abstract}
Minimally invasive surgeries provide lower morbidity and faster recovery compared to conventional surgeries. Since 1995, the cholecystectomy procedure shifted from conventional to minimally invasive by $80 \%$. Despite its popularity and benefits, minimally invasive surgeries have major complications, including vessel and organ injury from difficulties in distinguishing between the two. Currently, a decision to distinguish between vessel and nonvessels is mainly based on surgeon's experience and anatomical landmarks. Such methods can not only delay the operation time but also increase the number of medical errors due to subjectivity, especially for physicians-intraining. The purpose of this study is to introduce a sensor that can help distinguish blood vessels from non-blood vessel with a novel approach called "noninvasive impedance-based blood vessel detection". This approach utilizes a cost-effective, constant current source and voltage sensor that can offer a quick and non-invasive way to distinguish blood vessels during minimally invasive surgeries.
\end{abstract}

A unique characteristic of blood vessels is its pulsation. By capturing periodic dilation of the blood vessel, the validity of the blood vessel can be confirmed. Dilation of blood vessels not only changes flow resistance but also electrical resistance of blood vessel. By using a 50-100 uA current source with frequency from $1 \mathrm{kHz}$ to $10 \mathrm{MHz}$, small change in electrical resistance can be captured by a voltage detector. The detected periodic signal is compared to a reference value. If the signal is higher than the reference value, then the CMOS-based digital counter is used to determine whether the pulse is periodic enough to be signaled as a blood vessel.

Based on Ohm's law, Poiseuille's law, resistivity, and elasticity characteristics of blood vessel, minimal distention and changes in electrical resistance of the blood vessel based on pulse pressure can be analyzed. The minimum current needed to detect the change in resistance is mathematically deduced and compared with the measured results.

Another potential benefit of this approach is its versatility. Impedance-based sensing can easily be integrated into current minimally invasive instruments to avoid the necessity of additional equipment.

Keywords: Non-invasive blood vessel detection; Minimally invasive surgery; Impedance based blood vessel detection

\section{Introduction}

Minimally invasive surgeries refer to laparoscopic and roboticassisted surgeries where the procedures do not involve large, open incisions like traditional surgeries. Rather, tiny incisions are made and small tubes, video cameras, and surgical instruments are inserted through the tiny incisions and operations are performed. The major benefits of minimally invasive surgeries include, but are not limited to, lower morbidity, shorter hospital stay, and faster recovery [1].

Thanks to such benefits, today worldwide, minimally invasive surgery has become more common in hospitals [2]. In U.S. alone, 460,000 cholecystectomies, 500,000 hysterectomies, and 420,000 appendectomies are performed annually [3-5]. Since 1995, the rate of laparoscopic surgeries has been increasing tremendously and Table 1 shows the three most common surgeries in U.S.

Despite major advantages over conventional procedures, minimally

\begin{tabular}{|l|c|c|c|}
\hline Operation & $\begin{array}{c}\text { U.S. Annual } \\
\text { total } \\
\text { number }\end{array}$ & $\begin{array}{c}\text { Increase Rate } \\
\text { from 1995 to } \\
\mathbf{2 0 1 1}\end{array}$ & $\begin{array}{c}\text { Operation } \\
\text { Duration } \\
\text { (Minutes) }\end{array}$ \\
\hline $\begin{array}{l}\text { Laparoscopic } \\
\text { Cholecystectomy }\end{array}$ & 460,000 & $16 \%$ to $98 \%$ & 50 \\
\hline Laparoscopic Hysterectomy & 500,000 & $13 \%$ to $44 \%$ & 90 \\
\hline $\begin{array}{l}\text { Laparoscopic } \\
\text { Appendectomy }\end{array}$ & 420,000 & $13 \%$ to $75 \%$ & 45 \\
\hline
\end{tabular}

Table 1: Laparoscopic operation rate in U.S invasive surgeries are not without complications. Major complications include viscus injury and vessel injuries [6,7]. Although these listed injuries are inherent risks associated with surgeries, whether traditional or minimally invasive, the nature of not directly having access to the viscus in minimally invasive surgery, unlike conventional surgeries, can often delay the response time to accidents and can be more complicated [8]. To display the cause of such complications, Figure 1 illustrates the surgeons' view during laparoscopic operations (Figure 1).

As can be seen from Figure 1, one of the major challenges is that organ structures and blood vessels look very similar. For cholecystectomies, the hepatic artery and common bile duct appear very similar. Likewise, in hysterectomies, the uterine artery and ureter appear very similar to one another. Ligating either the common bile duct or ureter instead of the vessels can be detrimental [9].

Another challenge arising from the inability to objectively

*Corresponding author: Jae Kim, University of Central Florida College of Medicine, 6850 Lake Nona Blvd, Orlando, FL 32827, United States, Tel: (407)2661000; E-mail: jaekim@knights.ucf.edu

Received June 23, 2016; Accepted July 29, 2016; Published August 09, 2016

Citation: Kim J (2016) Non-Invasively Detecting Blood Vessels during Laparoscopic/Robotic Procedure. J Biosens Bioelectron 7: 214. doi: 10.4172/21556210.1000214

Copyright: @ $2016 \mathrm{Kim} \mathrm{J}$. This is an open-access article distributed under the terms of the Creative Commons Attribution License, which permits unrestricted use, distribution, and reproduction in any medium, provided the original author and source are credited. 
Citation: Kim J (2016) Non-Invasively Detecting Blood Vessels during Laparoscopic/Robotic Procedure. J Biosens Bioelectron 7: 214. doi: 10.4172/2155-6210.1000214

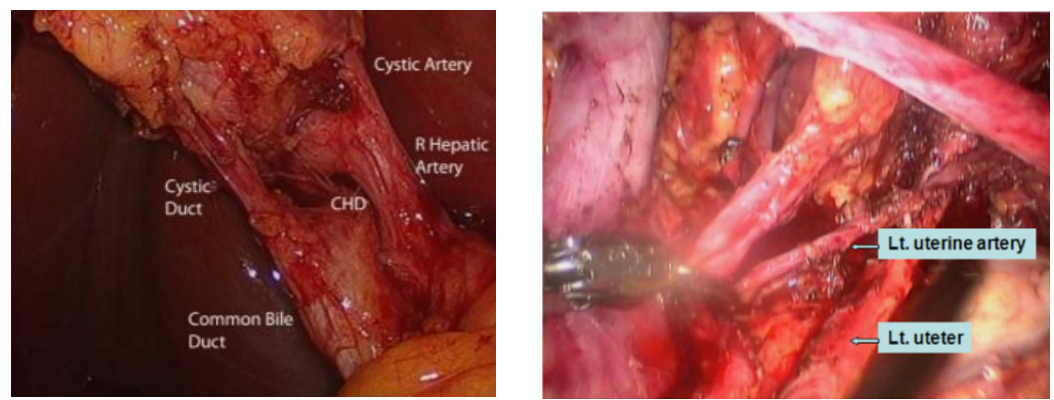

Figure 1: Laparoscopic Cholecystectomy (a) and (b) Laparoscopic Hysterectomy.
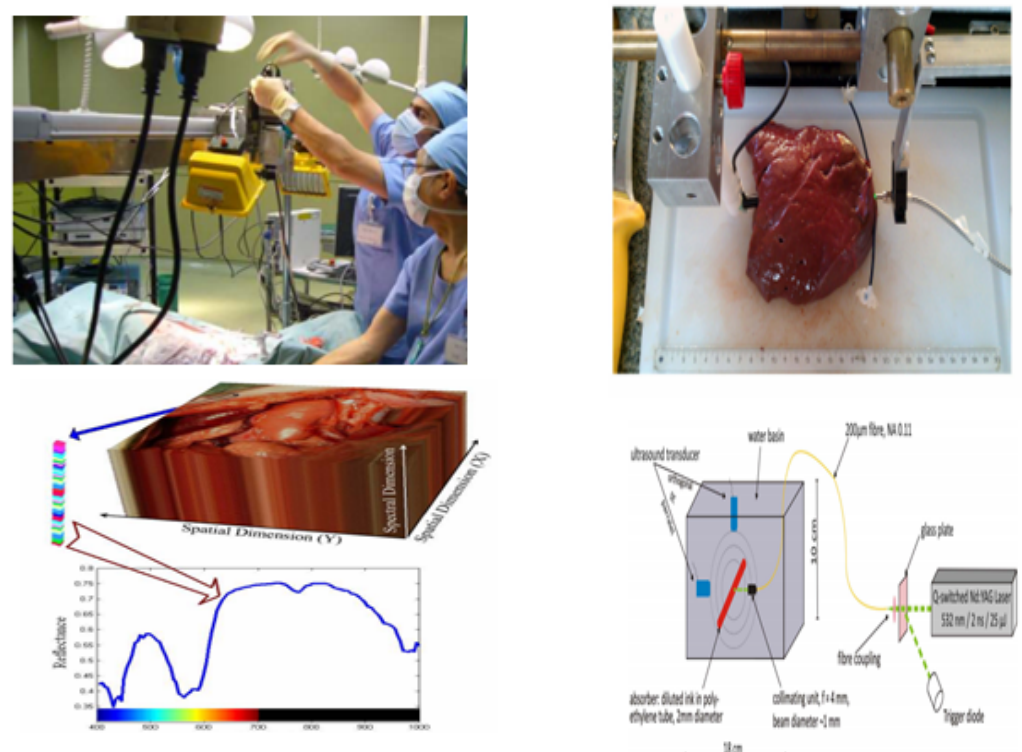

Figure 2: Current methods to detect the blood vessel: (a) spectral imaging and (b) photoacoustic

distinguish blood vessels is prolonged operation times. During laparoscopic cholecystectomy, $30 \%$ of the procedure time is spent identifying and ligating blood vessels [10]. For hysterectomies, it was reported that $50 \%$ of procedure time is spent identifying and ligating vessels [11]. Especially for physicians-in-training [12], identifying vessels can be even more challenging and easy areas to makes mistakes. Therefore, having an objective way to identify blood vessels can not only save operation time but also minimize medical errors.

Today, in order to distinguish between vessels and non-vessels, decisions are made mainly based on experience and discretion of surgeons, which is solely subjective. Therefore, accidental artery/ viscus ligation can happen unexpectedly [6] and oftentimes the surgery duration is prolonged.

Currently, there is no standardized way to detect blood vessels during operations. Akbari et al. [13] introduced vessel detection method based on spectral imaging, as shown by Figure 2(a). By using the spectral characteristics of arteries and hemoglobin, one can identify vessels among non-blood vessels. The spectral imaging method is unique and non-invasive but such method was not a practical option in the operating room (OR) setting. The spectral imaging method requires additional equipment in the OR, and preparing the equipment can be time-consuming. Any additional instrument in the sterile setting is a potential source of infection. Therefore, this method is not practical.

Horstmann et al. [14] introduced a vessel detection method based on a photoacoustic mechanism as shown by Figure 2(b). In this method, a laser is applied to the organs, including the vessels. Energy from the laser will excite and cause vibrations in molecules, and blood vessel will produce a unique vibration compared to organs nearby due to the fact that structures are composed of different densities. By detecting such vibrations, one can determine the presence of the vessel. The photo acoustic method is also non-invasive; however, like spectral imaging, such detection method requires additional instruments and is time-consuming. As a result, it is not a practical solution to be used in the OR setting (Figure 2).

As a potential solution to aforementioned limitations, the purpose of this project is to design and explore an impedance-based sensor to detect the blood vessels non-invasively in the OR setting. There were three goals for this project. The first goal is to design a cost-effective sensor that can detect blood vessels by utilizing the changes in electrical impedance of blood vessels. The second goal is to explore the feasibility of transforming a current laparoscopic instrument to include blood vessel sensing functionality instead of introducing an additional instrument to the OR. The third goal is to test if the prototype sensor can actually detect blood vessels whose diameters are 4-15 $\mathrm{mm}$, which 
Citation: Kim J (2016) Non-Invasively Detecting Blood Vessels during Laparoscopic/Robotic Procedure. J Biosens Bioelectron 7: 214. doi: 10.4172/2155-6210.1000214

Page 3 of 8

represents the majority of muscular arteries. Arteries in that range often cause confusion during surgeries, including the hepatic artery and uterine artery for cholecystectomies and hysterectomies, respectively.

Successful implementation and verification of the prototype carry major significance. An objective method in detecting blood vessels will minimize medical error, reduce OR time, and facilitate physicians in their early training. In addition, by transforming current laparoscopic/robotic instruments to include blood vessel sensing functionality, no additional instruments need to be introduced to the OR setting, which would not add an additional source of infection. Table 2 summarizes the comparison between existing methods and the proposed device (Table 2).

\section{Methods and Procedure: Theory Behind the Design}

\section{Blood vessel characteristics}

A unique characteristic of blood vessels compared to non-blood vessels is its pulsation. In a normal physiological setting, the heart beats 60-100 beats per minute and results in a pulsation that can be detected in multiple locations throughout the body, most commonly in the carotid arteries in the neck and radial arteries in the wrists. Physiologic changes in blood vessels are depicted in Figure 3(a).

"d1" represents the diameter of the blood vessel during the diastole period of the heart, and "d2" represents the diameter during the systolic. As blood flow is constant throughout the body [15], it can be expressed as

Flow $=\frac{\Delta P}{\text { Resistance }}=\frac{\Delta P \pi\left(d^{4}\right)}{8 \eta l}$
During pulsations, the resistance of blood vessels changes from

Resistance $1=\frac{8 \eta l}{\pi\left(\boldsymbol{d}_{1}^{4}\right)}$ to Resistance $2=\frac{8 \eta l}{\pi\left(\boldsymbol{d}_{2}{ }^{4}\right)}$

" $\Delta \mathrm{P}$ " is the difference in pressure along the blood vessel, " $\mathrm{d}$ " represents the diameter of the blood vessel, and " $\eta$ " represents the viscosity and " $l$ " represents the length of the blood vessel.

As shown in Figure 3(b), during pulsations, the resistance of the blood vessels changes from Resistance 1 to Resistance 2 .

\section{Measuring resistance based on Ohm's law}

Figure 4(a) shows a simplified model of this project. A constant current source will be generated and will be supplied through the blood vessels. Since the impedance across the blood vessel is less than the resistance of the systemic circulation, detected change in voltage across the blood vessel will represent the voltage across the vessels.

Figure 4(b) shows changes in impedance and voltage across the blood vessel when the pulse causes changes in resistance of the vessel. Such periodic signals can be detected to indicate that a structure is a blood vessel.

\section{Pressure difference and diameter distention}

Figure 5 shows the pulse pressure over different blood vessels, including arteries and veins.

Given empirical pulse pressure data, the average blood flow rate

\begin{tabular}{|c|c|c|c|}
\hline & $\begin{array}{c}\text { Hyperspectral Imaging } \\
\mathbf{( 2 0 0 9 )}\end{array}$ & $\begin{array}{c}\text { Photoacoustic Laser } \\
\text { (2011) }\end{array}$ & Noninvasive \\
\hline Methods & Noninvasive & Yes & Noninvasive \\
\hline Additional Device & Yes & High & Vory Low (<\$200) \\
\hline Cost & High & Technology Dependent & Technology Dependent \\
\hline Accuracy & Technology Dependent & Professional Supervision & Needed \\
\hline Procedure & Professional Supervision & Seeded & Slow \\
\hline Time to perform & Slow & Fast & \\
\hline
\end{tabular}

Table 2: Comparing current methods to proposed work.

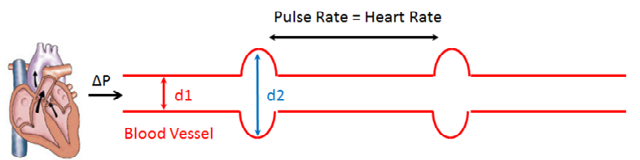

(a) Diameter Change

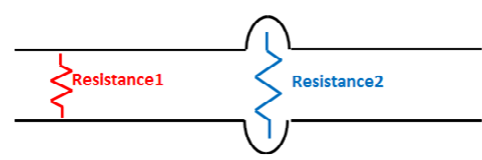

(a) Resistance Change

Figure 3: Blood vessel changes during pulsation in (a) diameter and (b) resistance.

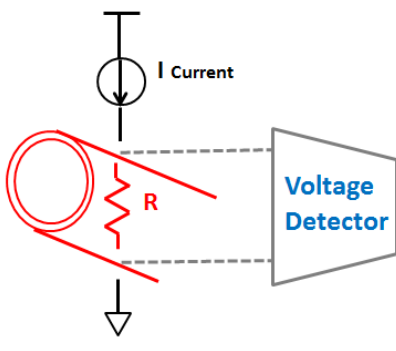

(a) Simplified Circuit

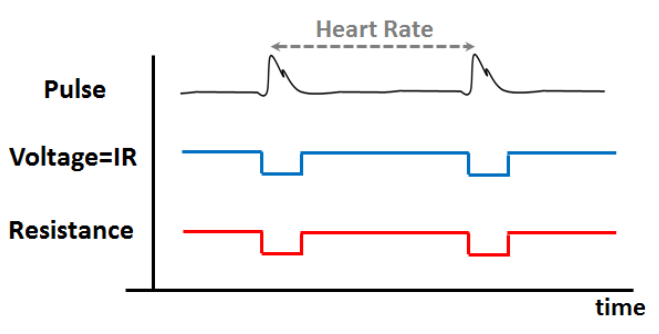

(b) Change in Resistance and Voltage, V=IR.

Figure 4: Simplified circuit model (a) and (b) resistance and voltage change with respect to pulsation. 
Citation: Kim J (2016) Non-Invasively Detecting Blood Vessels during Laparoscopic/Robotic Procedure. J Biosens Bioelectron 7: 214. doi: 10.4172/2155-6210.1000214

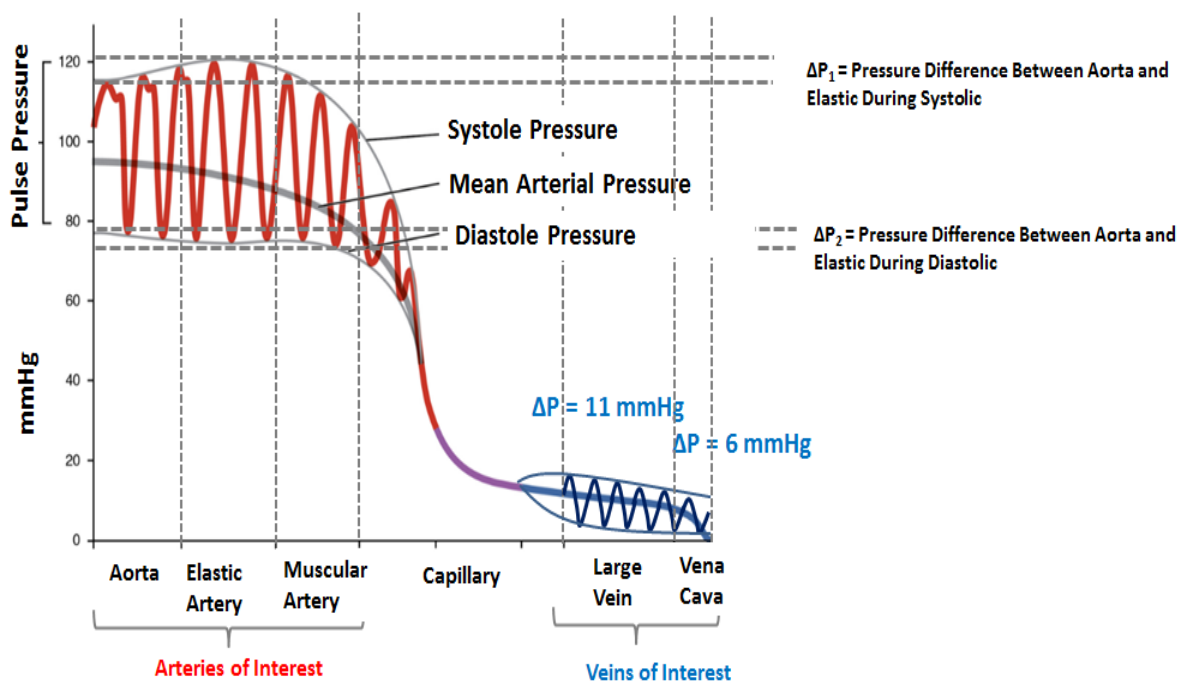

Figure 5: Pulse pressure for different vessels in the body.

\begin{tabular}{|c|c|c|c|c|}
\hline & Aorta & Elastic Artery & Muscular Artery & Medium Vein \\
\hline Pulse Pressure (mmHg) & 40 & 30 & 25 & 8 \\
\hline Average Diameter (mm) & 23 & 12 & 6 & 13 \\
\hline $\begin{array}{c}\text { Diameter Distention } \\
\text { with Pulse Pressure (mm) }\end{array}$ & 0.2 & 0.15 & 0.125 & 0.08 \\
\hline
\end{tabular}

Table 3: Pulse pressure and vessel distention information.

\begin{tabular}{|c|c|c|c|}
\hline Human Sample & Resistivity $\boldsymbol{\rho}(\mathbf{\Omega} \bullet \mathbf{m})$ & Prototype & Resistivity $\boldsymbol{\rho}(\mathbf{\Omega} \bullet \mathbf{m})$ \\
\hline Vessel Tissue & 71 & Silicon \\
\hline Blood & 1.5 & Normal Saline \\
\hline
\end{tabular}

Table 4: Resistivity comparison between blood and prototype.

of $5 \mathrm{~L} / \mathrm{min}$ through the heart [16] and elasticity of the different vessels throughout the body can be used to calculate the distention [17].

Distensibility $=\frac{\Delta V}{\Delta P}$ where $\Delta \mathrm{V}=$ change in volume and $\Delta \mathrm{P}=$ pulse
essure. pressure.

Volume Distention $=$ Distensibility $\bullet \Delta P=\Delta V=\frac{\Delta \text { Area } \bullet \text { Velocity }}{H R}$ where $\mathrm{HR}=$ heart rate

Velocity $=\frac{\text { Flow }}{\text { Nominal Area of Blood Vessel }}$

$\Delta V=\left(r_{2}^{2}-r_{1}^{2}\right) \pi \cdot \frac{Q}{\pi r_{1}^{2}} \cdot \frac{1}{H R}$

where $r_{2}=r_{1}+\Delta r$

$\left(\Delta r^{2}+2 \Delta r \cdot r_{1}\right)=\frac{\Delta V \cdot H R}{\text { Velocity }}=\frac{\text { Distention } \bullet \Delta P \cdot H R}{\text { Velocity }}$

where $2 \Delta r \cdot r \gg \Delta r^{2}$

Hence, overall distention relative to the $\Delta \mathrm{P}$ can be expressed as $\Delta r=\frac{\text { Distention } \bullet \Delta P \cdot H R}{\text { Velocity } \bullet 2 \cdot r}$

Using such relationship, Table 3 demonstrates pulse pressure and its associated distention information for different blood vessels (Table 3).

d. Diameter distention and change in electrical resistance, $\Delta R$.
The calculation for resistance with respect to diameter distention can be expressed as [18]:

$\boldsymbol{R}=\frac{\rho \cdot l}{\boldsymbol{r}^{2} \pi}$ where " $\rho$ " represents the resistivity and "l" represents the length

$$
\text { Where } \Delta P=\frac{\rho \bullet \lambda}{\rho^{2} \pi}-\frac{\rho \bullet \lambda}{(\rho+\Delta \rho)^{2} \pi}=\frac{\rho \bullet \lambda\left[(\rho+\Delta \rho)^{2}-\rho^{2}\right]}{\pi\left[\rho^{2}(\rho+\Delta \rho)^{2}\right]}
$$

The previous section explained the relationship between pulse pressure and distention of the blood vessel. By using this calculated distention, information on the changes in electrical resistance can be calculated by using the blood and vessel tissue resistivity information shown in Table 4 and resistivity equation shown above.

Understanding change in resistance is crucial as it allows us to calculate the minimal current needed to generate the desired voltage level that can be detected by the voltage detector. The expected current information can be compared to the level at which the heart rhythm can be affected [19].

\section{Overall architecture}

Figure 6 shows the overall architecture of this project. By using the binary digital to analog converter (DAC) current source, a constant current is injected through the two leads, as shown. The resulting voltage is measured through the same leads. The minimum voltage 
Citation: Kim J (2016) Non-Invasively Detecting Blood Vessels during Laparoscopic/Robotic Procedure. J Biosens Bioelectron 7: 214. doi: 10.4172/2155-6210.1000214

Page 5 of 8

required for detection is based on the noise and offset value of the voltage amplifier. Once the voltage is amplified, a comparator is used to compare the voltage to the threshold value. If a voltage above the threshold is detected, then the periodic signal detector, which is based on a digital counter, will be triggered. Once the counter counts up to the value of 30 within a 40 -second period, it indicates that a pulse has been detected and the result is displayed.

\section{Circuit implementation and data collection}

Figure 7 illustrates the actual circuit implementation of the architecture. A Voltage Controlled Oscillator (VCO) is used to generate the source voltage with frequency from $1 \mathrm{KHz}$ to $10 \mathrm{MHz}$. Such voltage drives a 5-bit current DAC with a $16 \mathrm{~mA}$ resolution. Then, a current is supplied to a blood vessel model and a reference resistance in-series. A non-inverting amplifier is used to amplify the small signal with the nominal gain of $20 \mathrm{~dB}$, which has an offset voltage of less than $5 \mathrm{mV}$. An amplified voltage is compared to the reference voltage generated by the resistor ladder. Two-input to single-ended output diode connected comparator is used to indicate the pulse. The digital counter based on CMOS D-Flip Flop is used to count the pulse generated by the comparator. To model the electrical characteristics of blood vessels and blood, silicon-based tubes (purchased from Advmedical) and normal saline (purchased from Allivet) are used. Lwasaki et al. [20] used silicone meshed with polyglycolic acid (PGA) and polycaprolactone (PCL) to design vascular grafts and engineer elasticity very similar to that of arteries with diameter of $6 \mathrm{~mm}$. In addition to the similarity in elasticity, more importantly for the purpose of this project, silicon and normal saline have similar resistivity characteristics to blood vessels and blood, as shown in Table 4 [21,22]. To model the circulation pump, an injection syringe pump (NE-1000 from PumpSystems) was used to circulate the saline. An alligator clip-based sensor is modified, as shown in Figure 8, to not only inject the current from the DAC but also to measure the voltage (Table 4 and Figure 8 ).

\section{Results}

\section{Maximum injectable current from the DAC current source}

According to Fish $\mathrm{R}$ et al. [23], an alternating current (AC) above $10 \mathrm{~mA}$ can affect the heart rhythm. To ensure patient safety, the maximum current is set to be $1 \mathrm{~mA}$ which is one-tenth of the allowable AC current. Therefore, blood vessels that require more than $1 \mathrm{~mA}$ to detect pulsations are considered non-detectable.

\section{Detectable vs Non-detectable blood vessels}

Figure 9(a) shows the change in resistance based on the distention for different blood vessels. Muscular arteries show the highest change in resistance over the vessel distention. A large change in resistance is desired, as it reduces the current needed to detect a minimal voltage; whereas small changes in resistance require higher currents (I). As power $(\mathrm{P})$ consumption is proportional to $\mathrm{I}^{2}$, large changes in resistance is desired more than small ones. Figure 9(b) shows the current consumption needed for different vessel sizes to be detected. The red dotted line indicates the $1 \mathrm{~mA}$ current set to be this project's maximum allowable current for safety concern. Such data indicates that the aorta and vena cava cannot be detected in less than $1 \mathrm{~mA}$ current. However, elastic arteries, muscular arteries, and medium veins can be detected with a current consumption of less than $1 \mathrm{~mA}$. This is a desired finding as most surgeries require being able to distinguish middle sized arteries from other organs, compared to the more obvious aorta or vena cava (Figure 9).

Based on $\Delta \mathrm{R}$ and current consumption, it is calculated that the range of blood vessel diameters that are detectable with less than 1 $\mathrm{mA}$ consumption is $2.4-18 \mathrm{~mm}$. With this range, Table 5 summarizes examples of blood vessels that can be detected (Table 5).

\section{Detecting hepatic artery and uterine artery}

As previously stated, elastic and muscular arteries with diameters

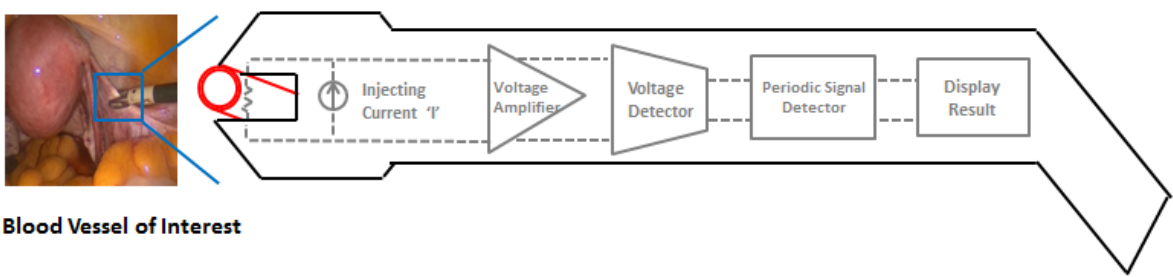

Figure 6: Overall architecture of the project.

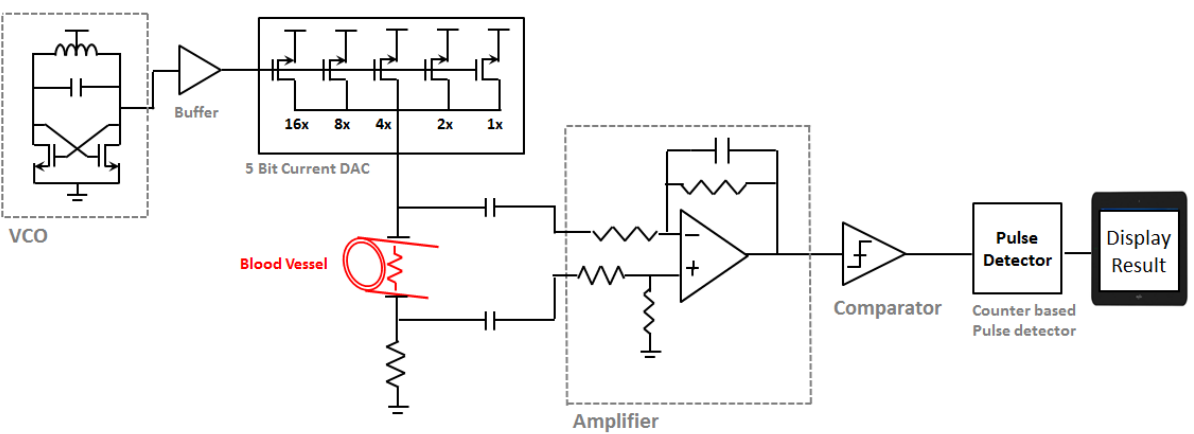

Figure 7: Circuit implementation of the overall architecture. 
Citation: Kim J (2016) Non-Invasively Detecting Blood Vessels during Laparoscopic/Robotic Procedure. J Biosens Bioelectron 7: 214. doi: 10.4172/2155-6210.1000214
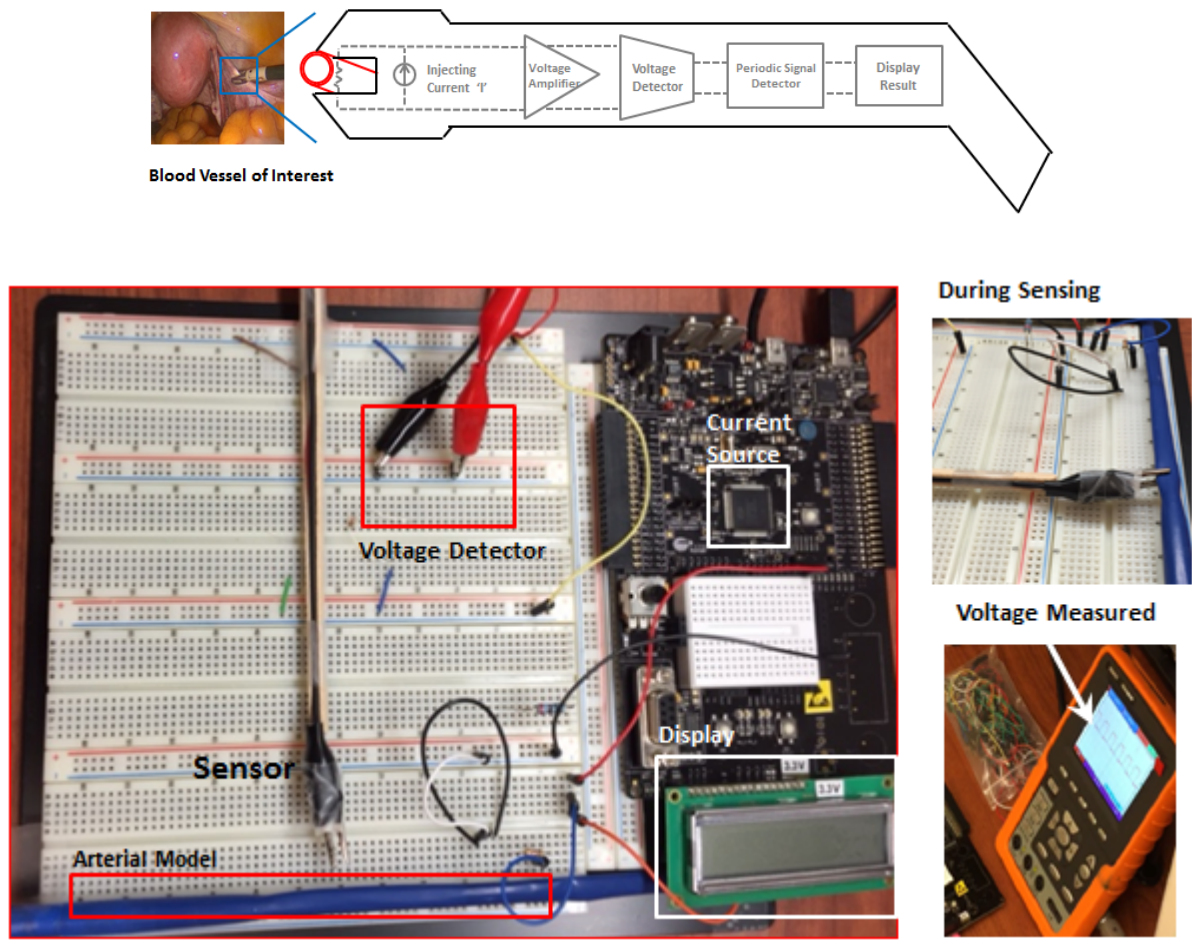

Figure 8: Blood vessel measurement prototype.

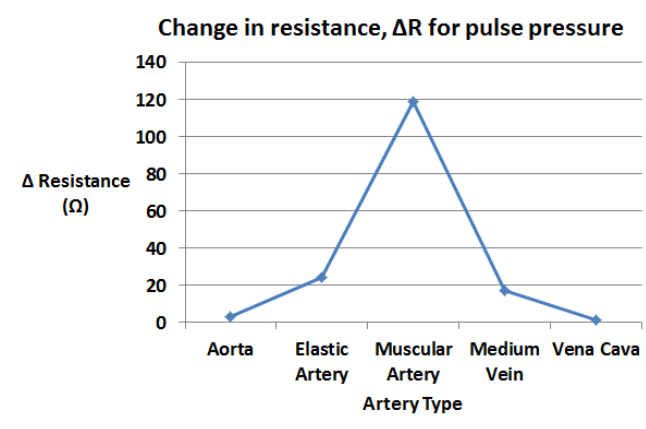

(a)

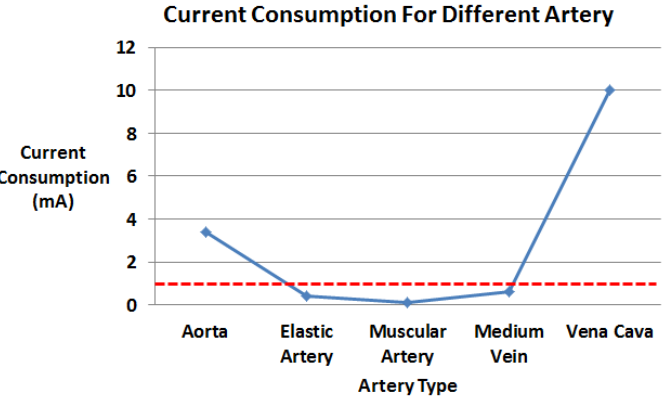

(b)

Figure 9: Different types of vessel characteristics: (a) change in resistance and (b) current consumption.

between 4 and $15 \mathrm{~mm}$ are often the blood vessels that present challenges during surgeries. Hepatic and uterine arteries are landmarks used to guide cholecystectomies and hysterectomies [3,4]. Therefore, designing a prototype with vessel diameters similar to those vessels carries important implications. Average diameters of the hepatic and uterine arteries are $4 \mathrm{~mm}$ and $5 \mathrm{~mm}$, respectively [24,25]. For the prototype, a flexible silicon tube with a diameter of $5 \mathrm{~mm}$ and wall thickness of 1 $\mathrm{mm}$ is used for the blood vessel model and $0.9 \%$ normal saline is used, along with the Alaris syringe pump, to model the circulatory system. The rate of the pump was set to 60 pumps/minute to model $60 \mathrm{bpm}$ heart rate. In order to detect the minimal power consumption, analog frequencies from $1 \mathrm{kHz}$ to $10 \mathrm{MHz}$ were investigated. Figure 10 shows the current and power consumption for different frequencies. Table 6 summarizes the comparison between calculations and measurements

\begin{tabular}{|c|c|c|}
\hline & Average Diameter & Detectable \\
\hline Aorta & $23 \mathrm{~mm}$ & No \\
\hline Celiac Trunk & $7.9 \mathrm{~mm}$ & Yes \\
\hline Left Gastric & $3.8 \mathrm{~mm}$ & Yes \\
\hline Uterine Artery & $4 \mathrm{~mm}$ & Yes \\
\hline Common Hepatic & $5 \mathrm{~mm}$ & Yes \\
\hline Common Iliac & $11 \mathrm{~mm}$ & Yes \\
\hline Portal Vein & $13 \mathrm{~mm}$ & Yes \\
\hline Vena Cava & $24 \mathrm{~mm}$ & No \\
\hline
\end{tabular}

Table 5: Blood vessels with diameter between 2.4 and $18 \mathrm{~mm}$ with less than $1 \mathrm{~mA}$ to be detected.

with error analysis between the two. As seen in Table 6, the VCO with a frequency of $100 \mathrm{KHz}$ produced a minimal current consumption with $50 \mathrm{uA}$ to detect the blood vessel. $50 \mathrm{uA}$ is $1 / 200^{\text {th }}$ of the current that 
Citation: Kim J (2016) Non-Invasively Detecting Blood Vessels during Laparoscopic/Robotic Procedure. J Biosens Bioelectron 7: 214. doi: 10.4172/2155-6210.1000214

Page 7 of 8

\begin{tabular}{|c|c|c|c|c|c|c|c|}
\hline \multirow[t]{2}{*}{ Frequency } & \multicolumn{2}{|c|}{ Calculated } & \multicolumn{2}{|c|}{ Measured } & \multirow{2}{*}{$\begin{array}{l}\text { Error } \\
(\%)\end{array}$} & \multirow{2}{*}{$\begin{array}{c}\text { Power } \\
\text { Consumption }\end{array}$} & \multirow{2}{*}{$\begin{array}{l}\text { Pulse } \\
\text { Detected }\end{array}$} \\
\hline & $\begin{array}{l}\text { Resistance } \\
(\Omega)\end{array}$ & $\begin{array}{c}\text { Current } \\
\text { (uA) }\end{array}$ & $\begin{array}{l}\text { Resistance } \\
(\Omega)\end{array}$ & $\begin{array}{c}\text { Current } \\
\text { (uA) }\end{array}$ & & & \\
\hline $1 \mathrm{KHz}$ & 140 & 71 & 160 & 63 & $11 \%$ & $63 \mathrm{uW}$ & Yes \\
\hline $10 \mathrm{KHz}$ & 132 & 76 & 170 & 58 & $23 \%$ & 57 uW & Yes \\
\hline $50 \mathrm{KHz}$ & 159 & 63 & 166 & 60.2 & $4 \%$ & $60 \mathrm{uW}$ & Yes \\
\hline $100 \mathrm{KHz}$ & 176 & 56 & 200 & 50 & $12 \%$ & $50 \mathrm{uW}$ & Yes \\
\hline $1 \mathrm{MHz}$ & 165 & 60 & 187 & 57 & $5 \%$ & $61 \mathrm{uW}$ & Yes \\
\hline $10 \mathrm{MHz}$ & 156 & 67 & 174 & 62 & $7 \%$ & $66 \mathrm{uW}$ & Yes \\
\hline
\end{tabular}

Table 6: Comparison between calculation and measurement for $5 \mathrm{~mm}$ vessel.

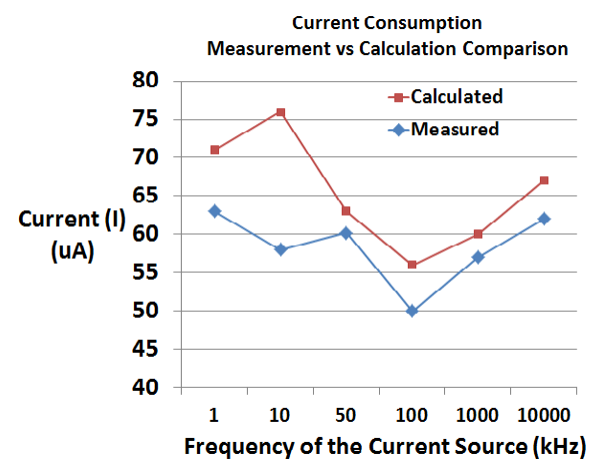

(a)

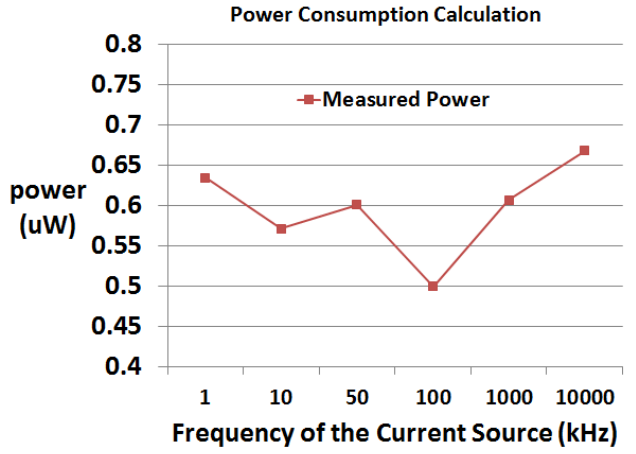

(b)

Figure 10: Current consumption between calculation and measurement over different frequencies (a) and (b) power consumption over frequencies.

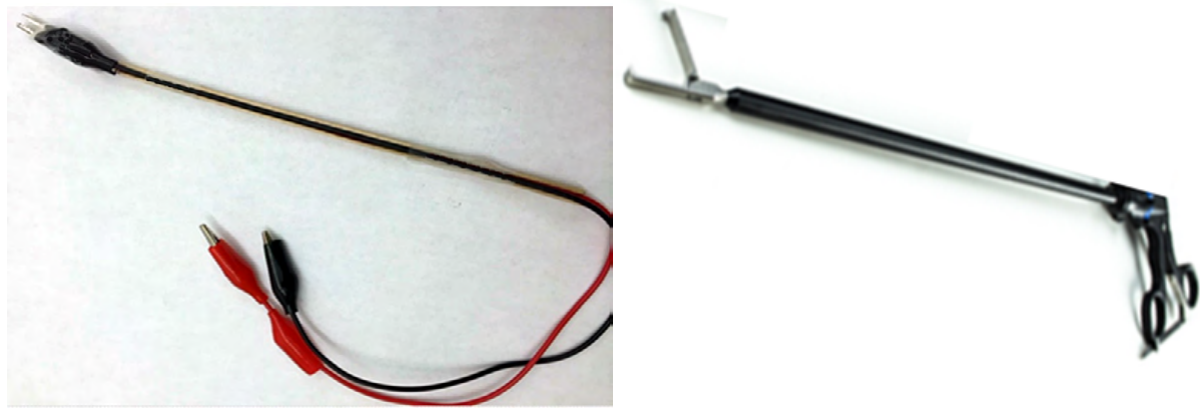

Figure 11: Sensor for this project (a) and (b) traditional laparoscopic instrument.

could potentially cause damage to human physiology. Such a small current validates the feasibility and power efficiency of this project (Figure 10 and Table 6).

\section{Integration to existing laparoscopic/robotic instrument}

Figure 11 compares the physical design of the impedance sensor designed for this project against the traditional laparoscopic instrument without sensing functionality. One of the purposes of this project was to explore the feasibility of integrating this sensing functionality into instruments currently in use. With the measurements presented in earlier sections and the advancement of semiconductor technology, there is no immediate limiting factor that prevents current DAC and voltage sensors from getting integrated.

\section{Discussion}

The main objective of this project was to build a low-cost impedancebased sensor to objectively distinguish blood vessels from non-blood vessels during minimally invasive procedures, such as laparoscopic and robotic surgeries. Furthermore, the purpose was to review the potential of the sensor to be integrated into currently used instruments rather than introducing an extra instrument. In order to accomplish such goal, a prototype sensor was developed and tested. Silicon tubes and normal saline were used to model the electrical characteristics of vessel tissue and blood, respectively.

The hypothesis was based on the unique pulsating characteristics of blood vessels. Pulsation causes a periodic change in diameter of the blood vessels and such change results in a change in electrical resistance also in a periodic manner. To capture the change in resistance, Ohm's law was used and a constant current was generated and supplied across the blood vessel. For the blood vessels of interest whose diameter ranges from $4 \mathrm{~mm}$ to $15 \mathrm{~mm}, 50 \mathrm{uA}$ at $100 \mathrm{KHz}$ provided the optimal power consumption to detect the periodic changes in resistance from the blood vessel and signal them as blood vessels. A physical model of the sensor was designed similarly to current laparoscopic instruments 
Citation: Kim J (2016) Non-Invasively Detecting Blood Vessels during Laparoscopic/Robotic Procedure. J Biosens Bioelectron 7: 214. doi: 10.4172/2155-6210.1000214

Page 8 of 8

to explore the possible integration of the sensing function. Low current consumption and proper functionality of the proposed design provides a promising insight on integration feasibility.

As a next step, it would be important to incorporate real vessel tissue and blood from animals. In addition, integrated circuits can be explored to merge all the functions described above into a single chip solution. This way, a small chip can be easily integrated into current laparoscopic instruments with sensing functionality.

\section{Conclusion}

An impedance-based sensor to detect blood vessels from nonblood vessels was developed. The accuracy (for vessels with diameter of 4-18 mm), cost, low power consumption (50 uA for detection), objectivity, and high likelihood of being integrated into current laparoscopic instruments will not only make the design versatile and affordable but also will help prevent subjective errors that often occur while identifying and ligating middle-sized blood vessels.

\section{Acknowledgment}

I would like to show the gratitude to my colleague, Sara Lee, for sharing her pearls of wisdom during the course of this research project.

\section{References}

1. Fuchs KH (2002) Minimally invasive surgery. Endoscopy 34: 154-159.

2. Cuschieri A (2005) Laparoscopic surgery: current status, issues and future developments. The surgeon: Journal of the Royal Colleges of Surgeons of Edinburgh and Ireland 3: 125-135.

3. Dua A, Aziz A, Desai SS, McMaster J, Kuy S (2014) National trends in the adoption of laparoscopic cholecystectomy over 7 years in the United States and impact of laparoscopic approaches stratified by age. Minimally invasive surgery 2014: 635461.

4. Wright JD, Herzog TJ, Tsui J (2013) Nationwide trends in the performance of inpatient hysterectomy in the United States. Obstetrics and gynecology 122: 233-241.

5. Nguyen NT, Zainabadi K, Mavandadi S (2004) Trends in utilization and outcomes of laparoscopic versus open appendectomy. American journal of surgery 188: 813-820.

6. Fruhwirth J, Koch G, Mischinger HJ, Werkgartner G, Tesch NP (1997) Vascular complications in minimally invasive surgery. Surgical Laparoscopy Endoscopy \& Percutaneous Techniques 7: 251-254

7. Nordestgaard AG, Bodily KC, Osborne RW, Buttorff JD (1995) Major vascula injuries during laparoscopic procedures. American journal of surgery 169 : 543-545.

8. Katkhouda N, Mason RJ, Towfigh S,. Gevorgyan A, Essani R (2005) Laparoscopic versus open appendectomy: a prospective randomized doubleblind study. Annals of Surgery 242: 439-450.

9. Manoucheri E, Cohen SL, Sandberg EM, Kibel AS, Einarsson J (2012) Ureteral
Injury in Laparoscopic Gynecologic Surgery. Reviews in Obstetrics and Gynecology 5: 106-111.

10. Stanisic V, Bakic M, Magdelinic M, Kolasinac H, Vlaovic D, et al. (2011) A prospective evaluation of laparoscopic cholecystectomy in the treatment of chronic cholelithiasis: a five-year experience. Medicinski pregled 64: 77-83.

11. Shushan A, Mohamed H, Magos AL (1999) How long does laparoscopic surgery really take? Lessons learned from 1000 operative laparoscopies. Human Reproduction 14: 39-43.

12. NÁCul MP, Cavazzola LT, de Melo MC (2015) Current status of residency training in laparoscopic surgery in Brazil: a critical review. Arquivos Brasileiros de Cirurgia Digestiva. Brazilian Archives of Digestive Surgery 28: 81-85.

13. Akbari H, Kosugi $\mathrm{Y}$, Kojima K, Tanaka N (2009) Blood vessel detection and artery-vein differentiation using hyperspectral imaging. Conference proceedings: Annual International Conference of the IEEE Engineering in Medicine and Biology Society. IEEE Engineering in Medicine and Biology Society. Annual Conference. pp: 1461-1464.

14. Horstmann J, Baade A, Brinkmann R, Lilge L (20011) Photoacoustic blood vessel detection during surgical laser interventions. Paper presented at: Medical Laser Applications and Laser-Tissue Interactions V.

15. Tsujino H, Shiki E, Hirama M, linuma K (1995) Quantitative measurement of volume flow rate (cardiac output) by the multibeam Doppler method. Journal of the American Society of Echocardiography: official publication of the American Society of Echocardiography 8: 621-630.

16. Kumar A, Minagoe S, Thangathurai D (1989) Noninvasive measurement of cardiac output during surgery using a new continuous-wave Doppler esophageal probe. The American journal of cardiology 64: 793-798.

17. Mackenzie IS, Wilkinson IB, Cockcroft JR (2002) Assessment of arterial stiffness in clinical practice. QJM 95: 67-74.

18. Singh B, Surplice NA (1972) The electrical resistivity and resistancetemperature characteristics of thin titanium films. Thin Solid Films 10: 243-253.

19. Hochberg HM (1971) Effects of electrical current on heart rhythm. The American Journal of Nursing 71: 1390-1394

20. Iwasaki K, Kojima K, Kodama S (2008) Bioengineered three-layered robust and elastic artery using hemodynamically-equivalent pulsatile bioreactor. Circulation 118: S52-S57.

21. Visser KR (1992) Electric conductivity of stationary and flowing human blood at low frequencies. Medical and Biological Engineering and Computing 30 636-640.

22. Kubarev SI, Shchedrin MI (1971) Electrical conductivity, electronic therma conductivity, and thermo-EMF of an organic semiconductor. Theoretical and Experimental Chemistry 4: 220-224

23. Fish RM, Geddes LA (2009) Conduction of electrical current to and through the human body: a review. Eplasty 9: e44.

24. Palmer SK, Zamudio S, Coffin C, Parker S, Stamm E, et al. (1992) Quantitative estimation of human uterine artery blood flow and pelvic blood flow redistribution in pregnancy. Obstet Gynecol 80: 1000-1006.

25. Kim WS, Cheon JE, Youn BJ (2007) Hepatic arterial diameter measured with US: adjunct for US diagnosis of biliary atresia. Radiology 245: 549-555. 